one of the greatest and best and most practical of subjects, and it holds more for the psychiatrists than anything else within their reach. I have wondered why the school teacher never takes into consideration what the inheritance of a certain child is, what its social environment is, what its particular adaptabilities and talents and characteristics are. They crowd down uniformly the same sort of discipline and the same sort of education and the same standard of grading for all children. There can be nothing less intelligent. We do not do that in the raising of live stock. Another thing that we are just beginning to recognize and apply definitely to this subiect is that all these little defects which, so far as the efficiency of the individual is concerned, are very important, have seemed to create a tendency even among ourselves to look on them as something that demanded exceptional ability. We have the tendency still, when we go to a show and see a man who pretends to be drunk to act as if there was something entertaining about seeing a man drunk. We are proud of our lack of control. But we have come to look on these deviations and derivations and mental defects or deficiencies as so many black marks under mental insufficiency, and that is where they belong. How we are going to stop crime and cure criminals is going to have a great deal to do with the wonderful change in our conception of these people and our methods of handling them.

Dr. H. Douglas Singer, Kankakee, Ill.: What I was trying to do in presenting this subject was not to arouse a philosophical discussion, but to stimulate an interest in it from a practical standpoint, for that is what we are working for at this stage. I believe the time is here when mental hygiene will have to be taken in hand practically. The various states are stirring up quite a little interest in it, although the medical schools are lagging behind. What are we trying to do? Educate the people. But we must consider it from the medicopsychiatric point of view. There is a great deal of work yet to be done.

\section{BLOOD PRESSURE STUDIES OF FIVE HUNDRED MEN}

BERTNARD SMITH, M.D. LOS ANGFLES

The studies for this report were made on men who applied for examination for the American Army Aviation Service. It may readily be seen that a long period of study could not be given to each applicant without causing unwarranted delay to the applicant and also to the other examiners. A Tycos instrument, daily tested with a mercurial sphygmomanometer, was used for all blood pressure estimations. All readings were made by one examiner in order to reduce the personal factor to as small an error as possible.

Readings were made with applicants in (1) the recumbent position; (2) standing, before exercise, and (3) standing, after measured exercise. The readings, in the first position, were made after the nervous excitement had become controlled as much as possible. This factor was commonly very prominent and often difficult to control, sometimes requiring the subject to return for a later reading. For the exercise test, a flight of twenty-four steps was used, each step having a 6-inch rise. Since the average weight was 142.6 pounds, the work performed averaged about 1,600 foot-pounds in five seconds. The area of cardiac dulness was estimated by percussion. The systolic and diastolic pressures were obtained by auscultation, and the diastolic pressure was read at the point of change from the third to the fourth phase. ${ }^{1}$ After the exercise test, the time required for the blood

1. Warfield, L. M. Studies in Auscultatory P1ood Pressure Phe nomena, Arch. Int. Med., September, 1912, p. 258. pressure to return to the previous standing point was noted in 200 of the men examined and recorded as recovery time.

The range and average of the readings in the recumbent position for the 400 cases that stood all tests as good normals are given in Table 1 .

I recognize the danger and, more often, the waste of time in the use of mathematical formulas for the interpretation of clinical findings. But a few such formulas have been so frequently used in blood pressure studies that I have arranged their values in Table 2 as derived from the first table.

TABLE 1.-RFADINGS FOR FOUR HUNDRED CASES IN RECCMBEN'T POSITION

\begin{tabular}{|c|c|c|c|c|c|c|c|c|c|}
\hline & \multirow{2}{*}{ Age } & \multirow{2}{*}{ P. R. } & \multirow{2}{*}{ S. P. } & \multirow{2}{*}{ D. P. } & \multirow{2}{*}{ P.P. } & \multicolumn{4}{|c|}{ Phase Lengths } \\
\hline & & & & & & 1 & 2 & 3 & 4 \\
\hline Range..... & $19-39$ & $78-94$ & $119 \cdot 132$ & $80 \cdot 88$ & $39: 44$ & $8 \cdot 18$ & $20 \cdot 26$ & $5-10$ & $4-6$ \\
\hline Average... & 24.2 & 85.4 & 127.7 & 84.1 & 42.2 & 12.1 & 24.5 & 6.2 & 5.1 \\
\hline
\end{tabular}

Tiegerstadt, using Strassburger's blood pressure quotient, measured the cardiac efficiency by dividing the velocity of the arterial flow by the work of the heart, and adopted the formula $\frac{P P}{S P} \times P R$, with an estimated normal value of from 30 to 35 per cent. ${ }^{2}$ Stone, ${ }^{3}$ recognizing the value of the diastolic pressure in estimating the heart load, adopted the formula $\frac{P P}{D P}$, with a normal value of 50 per cent. Goodman and Howell, ${ }^{4}$ in their studies of the auscultatory pressure phases, designated the second and third phases as measures of cardiac strength, and the first and fourth as the phases of cardiac weakness. From these studies they concluded that a cardiac strength factor greater than a cardiac weakness factor denotes a competent myocardium, especially if the second phase length equals more than 40 per cent. of the entire pulse pressure length. They determined the normal value of C. S.: C. W. as $55.4: 44.4$.

\begin{tabular}{l|c|c|c|c|c} 
TABLE 2.-PERCENTAGE & VALUES & DERIVED FROM TABLE 1 \\
\hline & $\begin{array}{c}\text { P. P. } \\
\text { S. P. }\end{array}$ & $\frac{\text { P. P. }}{\text { D. P. }}$ & C. S. \% & $\begin{array}{c}\text { Second } \\
\text { Phase } \\
\text { P. P. \% }\end{array}$ & $\begin{array}{c}\text { Crampton } \\
\%\end{array}$ \\
\hline Range......... & $29.8-36.9$ & $48.9-56.7$ & 54.1 .56 .6 & $46.2-62.6$ & $75-100$ \\
\hline Average........ & 33 & 50.2 & 50.8 & 57.4 & 86.9 \\
\hline
\end{tabular}

Crampton ${ }^{5}$ has worked out an ingenious table for measuring the percentage of vasomotor efficiency through the differences in the pulse rates and systolic pressures in the recumbent and standing positions. This table is based on the fact that the vasomotor tone is increased, normally, on changing from the recumbent to the upright position. Consequently the systolic pressure is increased and the pulse rate is either unchanged or slightly increased. In conditions of lowered vasomotor tone, the systolic pressure remains

2. Muller: Med. Klin., 1908, 1. 47.

3. Stone, W. J.: The Clinical Significance of High and Low Pulse Pressures with Special Reference to Cardiac Load and Overload, TuE Tournal A. M. A. Oct. 4, 1913, p. 1256.

4. Goodman and Howell: Am, Jour. Med. Sc., 1911, 142, 334.

5. Crampton, C. W.: New York Med. Jour., 1913, 93, No. 19. 
the same or is decreased on the change of position, and the pulse rate shows a definite increase.

The results for each person come well within the normal value given for each formula. The percentage ratio of Goodman and Howell's cardiac strength factor was persistently high and showed only the narrow percentage range of 2.5 in the 400 men examined. The ratio of the second phase to the value of the first, second and third phases, or the blood pressure length, shows a wider range and a high average. In several men, still in active training, a very prominent second phase was noticed. ${ }^{6}$ The length of this phase seemed to be at'the expense of the first and third, since the fourth phase was always of average length. Tonal arrhythmia, as described by Goodman and

TABLE 3.-RFADINGS AFTER FXERCISE

\begin{tabular}{l|c|c|c|c|c|c|c|c|c}
\hline & P. R. & S. P. & D. P. & P. P. & \multicolumn{3}{|c|}{ Pressure Phases } & $\begin{array}{c}\text { Recov. } \\
\text { Tine } \\
\text { Min. }\end{array}$ \\
\hline Range & $86-138$ & $128-158$ & $84-96$ & $44-68$ & $8-18$ & $24-49$ & $6-16$ & $6-9$ & $3.1-7.6$ \\
\hline Average & 112 & 145.4 & 90.6 & 54.1 & 13 & 33.5 & 11 & 7 & 4.4 \\
\hline
\end{tabular}

Howell, was never noticed in this group. In forty cases, or 10 per cent. of the total, a blurring of one or more of the phase tones was noticed. This was never so marked as to make the phase limit very difficult to recognize. Where this blurring was limited, it was usually found between the first and second phases, and in only two of the forty cases was it found limited to the third and fourth phases. These were cases showing intense excitement, difficult to overcome, in which readings taken two days later showed clear, normal, phase tones.

Table 3 gives the blood pressure findings after measured exercise, and a comparison with Table 1 shows the characteristic increase of both systolic and diastolic pressures after exercise, with the more marked increase in the former, causing an increase of pulse pressure. ${ }^{7}$ In the pressure phases, the most marked increase is in the second phase. ${ }^{8}$ This was true in each of the 400 cases, and it points with considerable emphasis to the importance of this phase in blood pressure interpretations. The least increase in the second phase, after 1,500 foot-pounds of work, was $4 \mathrm{~mm}$. In this series, the third pressure phase showed but little more increase after exercise than did the first and fourth phases.

In no case was the heart area found to be increased after the exercise, so far as could be determined by percussion and by the position of the apex impulse. In 31 per cent. of the cases, no change could be determined. In the remaining cases, there seemed to be a definite decrease in area. One hundred of the patients that showed a decreased area of dulness, after an average of 1,600 foot-pounds of stair-climbing in five seconds, were later given double this amount of exercise with a diminished cardiac dulness again in evidence.

It is to be regretted that the Barringer test ${ }^{9}$ could not have been carried out completely in these studies, and records made of the blood pressure findings.

6. Swan: Internat. Clin., 4, Series 24.

7. Norris: Internat. Clin., 1, Series 17 (biblography)

8, Fisher: Deutsch. Med. Wchnschr., 1908, 34, 1141.

9. Barringer, T. B.: The Circulatory Reaction to Graduate Work as a 'Test of the Heart's Functional Capacity, Arch. Int. Med., March, 1916, p. 363 .
In 200 cases, blood pressure readings were made immediately at the end of the exercise test and continued until the pressure returned to normal. In these, the apex of the systolic rise was reached in from 30 to 60 seconds after 1,600 foot-pounds of work. In the same group of 200 men, after double this amount of work, the highest point of the systolic rise was reached in 49.7 seconds; and the systolic pressure returned to its normal in from 3.1 to 7.6 minutes after the exercise, with an average recovery time of 4.4 minutes. These results agree with the general conclusions of Graupner, ${ }^{10}$ Barringer, Rapport, ${ }^{11}$ and other investigators, and show the normal increase, after work, in the systolic pressure, associated with lesser rise in the diastolic, with the resulting increase in pulse pressure. Associated with this systolic rise is a delayed return to normal after heavier work.

In the 400 normals, the pulse rate after exercise showed an average increase of 26.6 beats per minute, but returned to the quiet rate in from 2 to 5.5 minutes, with an average of 2.8 minutes. Definite tonal arrhythmia was not noticed in any of this group of normals.

In the following 100 cases which showed some variation from a strict normal, the findings were very complex, and diagnoses were usually impossible on blood pressure readings alone. All these men had had a more or less thorough routine physical examination that was recorded with their application papers. Consequently it is not surprising that very few cases showed some form of heart murmur. Five cases in all were detected, and these I have grouped for comparative study. Cardiac dulness was increased by the stair test in all five cases, and the breathing was objectively labored. Tonal arrhythmia was present in three cases-Cases 27, 84, 231. Table 4 gives the pressure readings in each of these cases.

The ratio of the second phase to the pulse pressure, after exercise, is found here to be low in each case, having a percentage variation of 28 to 46.1 compared with the values, before exercise, of 45.6 to 59.5 . The

TABLE 4.-PRESSURF READINGS IN FIVE CASES OF HEAR'T MURMUR

\begin{tabular}{|c|c|c|c|c|c|c|c|c|c|c|c|c|c|c|}
\hline \multirow{3}{*}{ No. } & \multicolumn{7}{|c|}{ Betore Exercise } & \multicolumn{7}{|c|}{ After Exercise } \\
\hline & \multirow{2}{*}{ S.P. } & \multirow{2}{*}{ D. P. } & \multirow{2}{*}{ P.P. } & \multicolumn{4}{|c|}{ Phases } & \multirow{2}{*}{ S. P. } & \multirow{2}{*}{ D. P. } & \multirow{2}{*}{ P. P. } & \multicolumn{4}{|c|}{ Phases } \\
\hline & & & & 1 & 2 & 3 & 4 & & & & 1 & 2 & 3 & 4 \\
\hline 27 & $12 f$ & 84 & 42 & 12 & 25 & 5 & 6 & 142 & 90 & 52 & 18 & 24 & 10 & 7 \\
\hline 34 & 126 & 84 & 42 & 10 & 22 & 10 & 7 & 132 & 88 & 44 & 18 & 22 & 14 & 9 \\
\hline 81 & 128 & 80 & 48 & 18 & 24 & 6 & 7 & 140 & 100 & 40 & 20 & 14 & 6 & 8 \\
\hline 220 & 148 & 80 & $\begin{array}{l}62 \\
62\end{array}$ & $2 \mathbf{i}$ & 34 & 7 & 10 & 182 & 96 & 86 & 39 & 37 & 10 & 14 \\
\hline 231 & 138 & 70 & 68 & 28 & 31 & 9 & 11 & 146 & 78 & 68 & 26 & 27 & 10 & 14 \\
\hline
\end{tabular}

C. S.: C. W. values are also slightly reduced after exercise when compared with their previous percentages, but to a less degree. These computations give us some basis for the diagnosis of myocardial weakness, but the same decision can be much more easily reached in noticing the change, in the cardiac area with exercise, in the dyspnea, and especially in the time required in each case for the pulse to drop to its previous rate. In these five cases the pulse rate recovery time was $10,12,15,14$ and 13 minutes, respectively. Case 27 at rest showed an indistinct mitral roughening that developed into a systolic murmur transmitted into the axilla after exercise. Case 34 showed the same finding at rest, and, after exercise, the mitral systolic

10. Graupner: Ztschr. f. exper. Path. u. Therap., 1906, 3, 113.
11. Rapport, D. L.: Systolic Blood Pressure Following Exercise, 11. Rapport, D. L.: Systolic Blo
Arch. Int. Med., June, 1917 , p. 981. 
murmur was transmitted through the left axilla and could be easily heard at the angle of the scapula. In both these cases there was definite accentuation of the pulmonic second sound. Case 84 showed no abnormal sounds at rest, but developed an aortic roughening and a mitral systolic murmur after exercise. Cases 220 and 231 showed an aortic roughening which was more marked after exercise. Cases 84,220 and 231 were all cases with hypertrophied tonsils and with slight subjective joint signs of absorption.

In five cases the radials were definitely palpable. All of these showed abnormal respiratory embarrassment with exercise and an increased recovery time of pulse rate. A comparison of the findings in these is given in Table 5 .

TABLE 5.-COMPARISON OF FINDINGS IN TIVE CASES IN WHICH 'I'HE RADIALS WERE PALPABLE

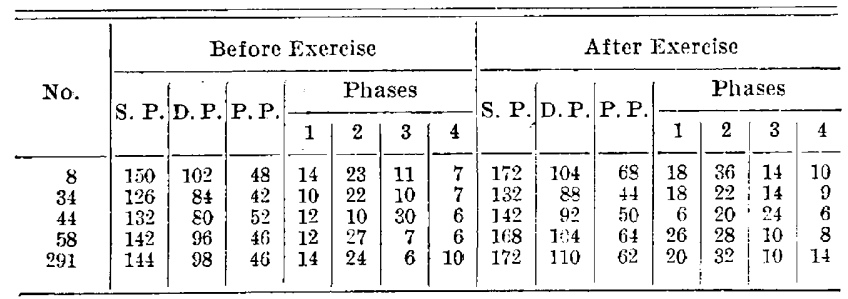

P. R. recovery time, $11,13,7,14,12$ minutes, respectively.

Pressure findings in this group also show wide variations. The C. S. factor was increased by exercise in all but one case (Case 58). But the ratio value of the second phase was increased only in Cases 8 and 44. The palpable radials constitute a finding probably of little importance in these men. They all show a limited physical efficiency. Patients 8 and 44 had hold office positions for several years, with little physical exercise, and impressed one as being persons to whom systematic exercise would be of real therapeutic value. With the exception of Case 34 , the men of this group are now all in other branches of active service and after three months of training are considered as physically fit. I have examined three of these men $(8,44$ and 58) after they had had two months of training and they showed a good normal response to exercise in every way.

Eleven applicants showed abnormally high systolic pressure with a high pulse pressure. Rest and quiet for half an hour failed to correct these high values. One of these inen had smoked twelve cigarettes in the morning before the examination. Six men had made an all-nigit automobile trip in order to be able to keep their appointment at the examining station. Four still showed signs of the previous night's dissipations. The pulse recovery time in these ranged from 4.5 to 6.5 minutes. After a twenty-four hour period of rest, these men all showed normal pressure values with normal responses to exercise.

One man (242) showed a systolic reading of 138 $\mathrm{mm}$., with a slightly increased pulse pressure. He had a low second phase ratio value after exercise and a Crampton reading of 52 per cent. The pulse recovery time was 5.5 minutes. Two days later he showed the exanthem of measles. After he had recovered, the pressure findings were normal. Recovery time was three minutes to 1,600 foot-pounds of work, and the Crampton reading was 92 per cent.

Eight men showed acute infections. Of these, three had acute tonsillitis, four had acute bronchitis and one acute laryngitis. Systolic pressure values ranged from 120 to $128 \mathrm{~mm}$. As the ages ranged from 28 to 36 years, these systolic readings are but little lowered. Pulse pressure readings ranged from 42 to 46 -only a little above normal ratios. Second phase ratios to pulse pressure were within normal limits during rest, but were low after exercise. Pulse recovery was delayed in each case, ranging from five to eight minutes after a rapid ascent of twenty-four steps. These men all returned for later examinations and showed normal findings.

Two cases showed hypotension (Cases 239 and 271). The systolic pressures were 98 and 101, with pulse pressures of 30 to $35 \mathrm{~mm}$, respectively. No abnormal heart findings were detected, aside from soft and distant sounds. Response to exercise was very poor in both cases. Case 239 showed a second phase ratio of 34 per cent. before exercise and 30 per cent. after 500 foot-pounds of work, also a pulse recovery time of ten minutes, markedly labored breathing with slight tonal arrhythmia in the first, second and third phases, and a Crampton value of 22 per cent. Hands and feet became markedly cyanosed on standing, but no other objective signs were noticed during the period of rest. This applicant gave a history of frequent fainting attacks after exercise and excitement. Case 271 had a second phase ratio of 38 per cent. after exercise and of 41 per cent. before. The pulse recovery time was 7.5 minutes. Labored breathing was observed after 600 foot-pounds of work, with a Crampton estimation of 42 per cent.

Thirty-eight cases showed some degree of tonal arrhythmia. In seven, this persisted through all the pressure phases. In nineteen, it was found through the first and second phases, and in twelve in the first phase only. Blood pressure findings during the periods of rest were normal in all of the thirty-eight. In all those showing arrhythmia throughout the phases, the response to 1,600 foot-pounds of work was poor. The pulse pressure was increased none, or very little, after

TABLE 6.-PRESSURF RECORD IN CASE OF PERSISTENT TONAL ARRHYTHMIA

\begin{tabular}{|c|c|c|c|c|c|c|c|c|c|c|c|c|c|}
\hline \multicolumn{7}{|c|}{ Before Exercise } & \multicolumn{7}{|c|}{ After Fxercise } \\
\hline \multirow{2}{*}{ S. P. } & \multirow{2}{*}{ D. $P$. } & \multirow{2}{*}{ P. P. } & \multicolumn{4}{|c|}{ Phases } & \multirow{2}{*}{ S. P. } & \multirow{2}{*}{ D. $\mathbf{P}$. } & \multirow{2}{*}{ P. P. } & \multicolumn{4}{|c|}{ Phases } \\
\hline & & & 1 & 2 & 3 & 4 & & & & 1 & 2 & 3 & 4 \\
\hline 136 & 91 & 45 & 10 & 28 & 7 & 6 & 164 & 116 & 48 & 19 & 17 & 12 & 16 \\
\hline
\end{tabular}

the exercise. The $C$. S. value and the second phase ratio were reduced. One pressure record (Table 6) will illustrate the findings in all the seven cases, as there was marked similarity.

In these seven cases, the Crampton percentage ranged from 52 to 68 per cent. Breathing was labored after the routine amount of exercise in each case, and the pulse recovery time ranged from 4 to 6.5 minutes. Two of the men mentioned slight distress over the mitral area after exercising. Four gave a history of dyspnea and some degree of precordial pain on forced exercise, which had obliged them to give up all athletics in school, except light gymnasium work. When the exercise was reduced to a figure of less than 600 foot-pounds, these men gave normal responses.

Blurring of the phases was present in all seven cases. The rest of the thirty-eight cases arrange. 
themselves fairly definitely, in groups of varying physical efficiency paralleling the extent of the arrhythmia. There was not sufficient time to test out each of these cases thoroughly with measured graduated exercises, but such tests could easily be made and used in determining the character of service men of this type are best able to give efficiently.

The remaining thirty applicants gave a blood pressure picture of nervous excitement, with increased systolic findings and a high pulse pressure. These cases showed normal physical findings, except for a slightly increased fulness of the pulse and a slightly lowered Crampton percentage of vasomotor efficiency. The systolic and diastolic pressures ranged from 140 to 158 and from 90 to 102 , at rest, and gave an increase of pulse pressure, after exercise, of from 6 to $10 \mathrm{~mm}$., slightly less than. the normals. No arrhythmia was present and no demonstrable increase in cardiac dulness. There was no blurring of the phase tones. Dyspnea was not marked in any case, and there were no distressing subjective symptoms. The ages of the thirty men ranged from 21 to 32 years. The blood pressure findings were similar to those in the cases of nervous excitement, but the condition could not be controlled by recumbent rest and quiet of more than one hour's duration at the examining station. Twenty-three of the men gave normal pressure findings within one week of daily observations, with general directions regarding sleep and avoidance of tobacco, coffee and other stimulants. Seven men were observed for two weeks, with very little change in the pressure findings and vasomotor percentages. In all these cases, the pulse recovery time was normal and the men responded well to the test of climbing fifty steps at good speed. The seven men have since entered the officers' training camps, and all have stood the work well.

Among the 400 cases reported as normals, twentythree showed high systolic and pulse pressures on the first reading. The systolic pressure in these cases frequently registered as high as $165 \mathrm{~mm}$., and in three cases it was recorded as high as $175 \mathrm{~mm}$. The diastolic pressure registered from 87 to 92 . Consequently, in several instances, the pulse pressure was almost equal to the diastolic. Physical findings were negative and after a short period of quiet, with occasionally some reassurance, the pressure findings dropped to normal. In one college athlete, aged 22 , the systolic pressure dropped from 174 to $128 \mathrm{~mm}$. in seventeen minutes. The Crampton estimate in these cases ranged from 75 to 80 per cent. after the systolic pressure had been reduced. Such cases emphasize the error of basing any opinion on single blood pressure readings, especially if unassisted by the exercise test.

Blood pressure findings alone are often of little value; especially is this true if we are trying to determine a man's physical fitness. The added information given through some form of measured exercise is of definite importance. The increase in the pulse rate with exercise is of no importance. In the 500 cases here reported, there was no marked difference noted between the increased rate of the normals and that of the unfit. ${ }^{12}$.

\section{Brockman Building.}

12. In addition to the references already given, the following will be found of interest:

Morris and Lane: Arch. Diagnosis, 1917, 10, 233.

Lewis, T.: Lancet, London, 1918, 1, 181.

\section{RETROPHARYNGEAL ABSCESS *}

\section{CALVIN C. RUSH, B.S., M.D. PHILADELPHIA}

The subject of retropharyngeal abscess is so vaguely understood by many general practitioners, and the results of an error in diagnosis may be so disastrous, that the report of a case should be of value.

The case is reported not on account of original material, but because of the lesson that it teaches. We are too prone to adopt the habit of looking for the usual condition in a part affected, and to overlook the unusual condition when it appears. The careless physician commits the sin of assuming the usual condition. In this case the baby's life could have been saved in hardly more time than a physician would consume in putting on his overcoat. One of two conclusions must be drawn, either a physician was not called or, having been called, was negligent. A digital examination would have given him the diagnosis.

No history of the disease can be given. The body of a negro baby, aged 2 years, being unclaimed, became the property of the State anatomical board and was delivered to the Daniel Baugh Institute of Anatomy of the Jefferson Medical College of Philadelphia for scientific purposes. The preservation being poor, the body was valueless for routine study. A midsagittal section was fortunately made by $\mathrm{Dr}$. Schaeffer after first hardening the body in solution of formaldehyd. This disclosed the condition that is well shown in the accompanying illustration. An abscess measuring $3 \mathrm{~cm}$. in length and width was found in the retropharyngeal space. It extended forward $2 \mathrm{~cm}$. to the uvula and epiglottis, completely obstructing the pharynx and larynx. The abscess cavity was much shrunken by the action of the formaldehyd and in the living state was, doubtless, much larger. An examination of the body gave no definite clue as to the cause of the abscess. A prominent pharyngeal tonsil was present.

The development and course of retropharyngeal abscess is better understood if one keeps in view the the different layers of tissue that intervene between the pharynx and the cervical vertebrae.

Dorsal to the mucous membrane of the pharynx is the pharyngeal aponeurosis, a loosely attached fascia permitting of free movement and free swelling. This fascia is followed by the constrictor muscles, which are in turn covered by the thin buccopharyngeal fascia. This fascia is but loosely attached by areolar tissue to the strong prevertebral fascia which follows. The loose areolar tissue space-the retropharyngeal space-permits of free expansion. The strong prevertebral fascia covers the prevertebral muscles which overlie the cervical vertebrae. It is evident, when pus forms dorsal to the prevertebral fascia and is confined there, that extension must be limited, whereas, if present ventral to the fascia, in the loose retropharyngeal fascial space, the freest extension is possible.

The source of infection leading to abscesses posterior to the pharynx are usually classified under four headings :

1. Those due to caries of the upper cervical vertebrae, usually of tuberculous origin. Such an abscess, being dorsal to the prevertebral fascia, is very

* From the Daniel Baugh Institute of Anatomy, Jefferson Medical College. 